\title{
Expanding and Enhancing Federal, State, Tribal, and Academic Partnerships to Advance the Field of Maternal and Child Health
}

\author{
Charlan D. Kroelinger • Wanda D. Barfield • \\ William M. Callaghan
}

Published online: 30 November 2012

(C) Springer Science+Business Media New York (outside the USA) 2012

Collaboration is the foundation for producing sound programmatic and scientific work in public health. As far back as the late 1800s, when the field of public health was in its infancy in the United States, collaboration and partnership among existing agencies including the American Public Health Association, Congress, state and city boards of health, and state legislatures provided the basis for development of fundamental policies including sanitation, the standardization of laboratory methodologies, vaccination protocols, and implementation of quarantine measures during disease outbreaks $[1,2]$. In the mid to late twentieth century, international eradication of smallpox and in the early twenty-first century near global eradication of polio announced by agencies included in the World Health Assembly are examples of how collaboration in science and medicine impact health at the population level on a large scale [3, 4].

In the field of maternal and child health $(\mathrm{MCH})$, there are a multitude of examples which demonstrate how collaboration has propelled research and practice forward, including development of regionalized systems of care for at-risk neonates, understanding the link between human papilloma virus and cervical cancer, and determining the effects of obesity on development of chronic conditions among women of reproductive age $[5,6]$. With the

Disclaimer The findings and conclusions in this report are those of the authors and do not necessarily represent the official position of the Centers for Disease Control and Prevention.

C. D. Kroelinger $(\bowtie) \cdot$ W. D. Barfield · W. M. Callaghan Division of Reproduction Health, National Center for Chronic Disease Prevention and Health Promotion, Centers for Disease Control and Prevention, 4770 Buford Hwy NE, MS K-22,

Atlanta, GA 30341, USA

e-mail: ckroelinger@cdc.gov dynamic health care environment, public health has adapted to changing systems and focused on the quality of care; but the foundational importance of collaboration and partnership has remained the same. This Maternal and Child Health Journal Supplement describes model partnerships and collaborative efforts among federal, state, tribal, and academic agencies, including a partnership between the Centers for Disease Control and Prevention (CDC) and the University of Illinois at Chicago (UIC) to implement a multi-year distance-based initiative that resulted in analyses of complex sample surveys in women's health, children's health, and access to care that was fundamental to supporting efforts to address key $\mathrm{MCH}$ issues including (1) research to highlight disparities among specific populations, (2) development of national strategies and application of existing models to reduce fetal and infant mortality in states; and (3) the advancement of $\mathrm{MCH}$ leadership and innovation in developing the workforce, with perspectives provided to move the field forward.

To address needs of state epidemiology and program staff, CDC's Maternal and Child Health Epidemiology Program, which places senior level $\mathrm{MCH}$ epidemiologists in states and agencies, developed a distance-based initiative in partnership with UIC to provide workforce development in advanced analytic methodologies to state staff [7]. The most recent products from this initiative include the analyses of complex-sample surveys, such as the Behavioral Risk Factor Surveillance System, the National Survey of Children's Health, and the Pregnancy Risk Assessment Monitoring System (PRAMS) by twelve stateled teams to address issues of state, regional, and national importance to $\mathrm{MCH}$ populations. These products are published within this supplement and are organized around three themes: women's health, children's health, and access to care. Whether examining geographic variation 
and trend data in new ways, integrating disparate datasets, reporting recently developed measures from multilevel modeling, or extending the use of mediation analysis, all of this collaborative state-led work incorporates innovative approaches to enrich the reader's understanding of complex MCH issues.

In the area of women's reproductive health, Willet et al. [8] focus analyses on how women's social-emotional support, life satisfaction, and mental health status affect whether they have a routine medical check-up. Likewise, Hernandez et al. [9] report on long-acting reversible contraceptive use among reproductive aged women in Florida, describing the overall trend in effective use as well as trends in the types of effective methods Florida women choose. D'Angelo et al. [10], using national PRAMS data, identify risk factors and behaviors during and after pregnancy that may be addressed by extending coverage for preventive services postpartum, while Ahluwalia et al. [11] focus on the how the type of delivery affects breastfeeding duration. Short et al. [12] estimate the prevalence of preconception health indicators in thirteen contiguous states among non-pregnant reproductive aged women residing in Appalachian and non-Appalachian counties, and also among Appalachian women residing within Appalachian counties according to economic status. Similarly, Bish et al. [13] examine the same preconception health indicators among women who reside in the Mississippi Delta compared with women who reside in the remainder of Mississippi, in the other Delta states, and the rest of the U.S.

Four state teams focus on children's health issues, with an emphasis on physical activity, overweight and obesity, mental health status, and social behaviors. Kasehagen et al. describe how neighborhood characteristics are associated with attainment of minimum physical activity levels comparing a continuum of isolated rural to dense urban communities [14]. In the seven state analysis provided by Ness et al., risk factors for overweight and obesity among American Indian and Alaska Native children are compared with white children to determine if differences exist between these populations and to identify recommendations for targeted public health interventions [15]. Lu et al. [16], examine weight status in Massachusetts youth and its association with markers of mental health, including negative behaviors or emotions, and diminished social skills. Robl et al., study active parental involvement and social behavior among children in Kentucky compared with children in the U.S. [17].

The final set of analyses conducted in the distance-based initiative focus on access to care; specifically, access to routine screening for women of reproductive age, quality care for children in Georgia, preventive dental care among children across states, and racial disparities in unmet needs among children with special health care needs. Herrera et al. [18] compare prevalence of recent Papanicolaou screening among U.S. and Mexican border resident women, and examine factors associated with screening differences. In their paper, Ogbuanu et al. [19], focus on factors associated with access to quality care in Georgia. When examining access to dental care among children, Lin et al. [20], consider the associations between state level and individual level factors with lack of preventive dental care. Bennett et al. [21] examine the extent to which access to a medical home explain the racial disparity in unmet healthcare needs among children with special health care needs. Taken together, the findings from all twelve studies conducted by the state teams participating in the CDC/UIC initiative highlight the role partnerships play in enhancing $\mathrm{MCH}$ research, program planning and implementation, targeting of resources, and policy formation.

Partnerships are also essential when communicating analytic findings to reduce disparities in $\mathrm{MCH}$. Two articles in this supplement highlight the importance of federal, state, and tribal partnerships in supporting analysis and publication of epidemiologic research. Such partnerships provide the capacity to support analyses of these at-risk populations and the resources for wider dissemination of findings. Rutman et al. [22] use National Survey of Family Growth data to examine sexual violence against young urban American Indian/Alaska Native women, and Cunningham et al. [23] explore the association between a mother's perception of food security and options for her toddler in a food insecure environment.

Infant mortality rates have not significantly improved in the U.S. for the last decade and disparities remain. Each state has focused on addressing infant mortality at the community level, state level, and regionally through multiple consortiums, task forces, and collaboratives, and two articles in this supplement provide examples of this work. The state of Louisiana has invested in an effort to implement nine regional Fetal and Infant Mortality Review (FIMR) programs, collaborating on a large scale to understand fetal and infant deaths throughout the state [24]. Kieltyka et al., describe how the state of Louisiana has adapted the national FIMR model into a coordinated network of regional teams that incorporate continuous quality improvement processes. To further address infant mortality, federal, state, and non-governmental agencies initiated the State Infant Mortality Collaborative (SIMC) [25] with the purpose of developing a standard approach to examining infant mortality in states. Five state teams participated in the SIMC to develop strategies in three domains: data reporting, cause and timing of infant death, and issues related to maturity and birth weight. These strategies produced findings that were used to affect program and policy change in each participating state. Both of these articles 
illustrate the impact of collaboration; whether partnerships occur at the community, state, or national level, they can result in the advancement of programs and policies that build the foundation for evidence-based practice.

The supplement also includes two articles specifically addressing leadership which is central to collaboration and partnership. Leadership is achieved in the field of $\mathrm{MCH}$ through workforce development and peer exchange. Phillips et al. [26], comment on the growth of the $\mathrm{MCH}$ field through doctoral training programs, internships and fellowships, applied training for professionals, and short and long term skills building. Kroelinger et al. [27], analyzed data collected from an evaluation of the annual $\mathrm{MCH}$ Epidemiology Conference which focused on the attendees' thoughts on a wide array of possible leadership initiatives. The practical recommendations presented in these two papers further highlight the need for strengthened partnerships between agencies and institutions to provide the training necessary for supporting the research, the programs, and the development of relevant policy for women, infants, children, and families.

Finally, the following editorial truly emphasizes the purpose of this supplement: to push the thinking of those in the field of $\mathrm{MCH}$ beyond building individual skills through workforce development and training to an expanded focus on MCH scientific capacity in the context of a larger public health system [28]. With this perspective, collaboration has a broader reach and leadership a wider impact on $\mathrm{MCH}$ program infrastructure - at local, state, and national levels.

This supplement provides innovative commentary, analyses, and research aimed at encouraging collaboration among epidemiologists and those responsible for implementing, evaluating, and advocating for $\mathrm{MCH}$ programs and policies to improve the public's health.

\section{References}

1. Bryce, P. (1918). History of the American Public Health Association. American Journal of Public Health, 8, 327-335.

2. Greenberg, M. (2012). Sanitation and public health: A heritage to remember and continue. American Journal of Public Health, 102, 204-206.

3. Henderson, D. (1999). Eradication: Lessons from the past. Morbidity and Mortality Weekly Reports Supplement, 48, 16-22.

4. Hull, H., De Quadros, C., Bilous, J., et al. (1999). Perspectives from the global poliomyelitis eradication initiative. Morbidity and Mortality Weekly Reports Supplement, 48, 50-56.

5. Toward improving the outcome of pregnancy. (1977). Recommendations for the regional development of maternal and perinatal health services. White Plains, NY: National March of Dimes Foundation.

6. Toward improving the outcome of pregnancy. (1993). The 90s and beyond. Wilkes-Barre, PA: National March of Dimes Birth Defects Foundation.
7. Rankin, K. M., Charlan D. Kroelinger, C. D., Rosenberg, D., \& Barfield, W. D. (2012). Building analytic capacity, facilitating partnerships, and promoting data use in state health agencies: A distance-based workforce development initiative applied to maternal and child health epidemiology. Maternal and Child Health Journal. doi:10.1007/s10995-012-1190-9.

8. Willet, M. N., Hayes, D. K., Zaha, R. L., \& Fuddy, L. J. (2012). Social-emotional support, life satisfaction, and mental health on reproductive age womens' health utilization, US, 2009. Maternal and Child Health Journal. doi:10.1007/s10995-012-1096-6.

9. Hernandez, L. E., Sappenfield, W. M., Clark, C., \& Thompson, D. (2012). Trends in contraceptive use among Florida women: Implications for policies and programs. Maternal and Child Health Journal. doi:10.1007/s10995-012-1097-5.

10. D’Angelo, D. V., Williams, L., Harrison, L., \& Ahluwalia, I. B. (2012). Health status and health insurance coverage of women with live-born infants: An opportunity for preventive services after pregnancy. Maternal and Child Health Journal. doi:10.1007/s10995-012-1172-y.

11. Ahluwalia, I. B., Li, R., \& Morrow, B. (2012). Breastfeeding practices: Does method of delivery matter? Maternal and Child Health Journal. doi:10.1007/s10995-012-1093-9.

12. Short, V. L., Oza-Frank, R., \& Conrey, E. J. (2012). Preconception health indicators: A comparison between non-Appalachian and Appalachian women. Maternal and Child Health Journal. doi:10.1007/s10995-012-1129-1.

13. Bish, C. L., Farr, S., Johnson, D., \& McAnally, R. (2012). Preconception health of reproductive aged women of the Mississippi River Delta. Maternal and Child Health Journal. doi:10.1007/ s10995-012-1166-9.

14. Kasehagen, L., Busacker, A., Kane, D., \& Rohan, A. (2012). Associations between neighborhood characteristics and physical activity among youth within rural-urban commuting areas in the US. Maternal and Child Health Journal. doi:10.1007/s10995012-1188-3.

15. Ness, M., Barradas, D. T., Irving, J., \& Manning, S. E. (2012). Correlates of overweight and obesity among American Indian/ Alaska Native and non-Hispanic white children and adolescents: National Survey of Children's Health, 2007. Maternal and Child Health Journal. doi:10.1007/s10995-012-1191-8.

16. Lu, E., Dayalu, R., Diop, H., Harvey, E. M., Manning, S. E., \& Uzogara S. G. (2012). Weight and mental health status in Massachusetts, National Survey of Children's Health, 2007. Maternal and Child Health Journal. doi:10.1007/s10995-012-1145-1.

17. Robl, J. M., Jewell, T. D., \& Kanotra, S. (2012). The effect of parental involvement on problematic social behaviors among school-age children in Kentucky. Maternal and Child Health Journal. doi:10.1007/s10995-012-1187-4.

18. Herrera, D. G., Schiefelbein, E. L., Smith, R., Rojas, R., Mirchandani, G. G., \& McDonald, J. A. (2012). Cervical cancer screening in the US-Mexico border region: A binational analysis. Maternal and Child Health Journal. doi:10.1007/s10995-0121130-8.

19. Ogbuanu, C., Goodman, D. A., Kahn, K., Long, C., Noggle, B., Bagchi, S., et al. (2012). Timely access to quality health care among Georgia children ages 4 to 17 years. Maternal and Child Health Journal. doi:10.1007/s10995-012-1146-0.

20. Lin, M., Sappenfield, W., Hernandez, L., Clark, C., Liu, J., Collins, J., et al. (2012). Child- and state-level characteristics associated with preventive dental care access among U.S. children 5-17 years of age. Maternal and Child Health Journal. doi:10.1007/s10995-012-1099-3.

21. Bennett, A. C., Rankin, K. M., \& Rosenberg, D. (2012). Does a medical home mediate racial disparities in unmet healthcare needs among children with special healthcare needs? Maternal and Child Health Journal. doi:10.1007/s10995-012-1131-7. 
22. Rutman, S., Taualii, M., Ned, D., \& Tetrick, C. (2012). Reproductive health and sexual violence among urban American Indian and Alaska Native young women: Select findings from the National Survey of Family Growth (2002). Maternal and Child Health Journal. doi:10.1007/s10995-012-1100-1.

23. Cunningham, T. J., Barradas, D. T., Rosenberg, K. D., May, A. L., Kroelinger, C. D., \& Ahluwalia, I. B. (2012). Is maternal food security a predictor of food and drink intake among toddlers in Oregon? Maternal and Child Health Journal. doi:10.1007/ s10995-012-1094-8.

24. Kieltyka, L., Craig, M., Goodman, D. A., Wise, R. (2012). Louisiana implementation of the national fetal and infant mortality review (NFIMR) program model: Successes and opportunities. Maternal and Child Health Journal. doi:10.1007/s10995012-1186-5.

25. Stampfel, C., Kroelinger, C. D., Dudgeon, M., Goodman, D., Ramos, L. R., \& Barfield, W. D. (2012). Developing a standard approach to examine infant mortality: Findings from the State
Infant Mortality Collaborative (SIMC). Maternal and Child Health Journal. doi:10.1007/s10995-012-1167-8.

26. Phillips, G., Sappenfield, W., Handler, A., \& Kogan, M. D. (2012). Promoting a trained MCH epidemiology workforce in state public health agencies through strategies developed from continued partnerships. Maternal and Child Health Journal. doi:10.1007/s10995-012-1095-7.

27. Kroelinger, C. D., Kasehagen, L., Barradas, D. T., \& 'Ali, Z. (2012). Building leadership skills and promoting workforce development: Evaluation data collected from public health professionals in the field of maternal and child health. Maternal and Child Health Journal. doi:10.1007/s10995-012-1098-4.

28. Rosenberg, D., Barfield, W. D., Rankin, K., \& Kroelinger, C. D. (2012). Increasing scientific and analytic capacity in states: Extending epidemiology collaborations beyond traditional workforce development. Maternal and Child Health Journal. doi:10.1007/s10995-012-1189-2. 